\title{
Microsatellite and mating type primers for the maize and sorghum pathogen, Exserohilum turcicum
}

\author{
M.P. Haasbroek, M. Craven, I. Barnes and B.G. Crampton*
}

I. Barnes and B. G. Crampton are senior authors who contributed equally to this article.

\author{
M. P. Haasbroek • B. G. Crampton $\left(^{*}\right)$ \\ Department of Plant Science, Forestry and Agricultural Biotechnology Institute (FABI), University of Pretoria, Pretoria 0002, South Africa \\ e-mail: bridget.crampton@up.ac.za \\ I. Barnes \\ Department of Genetics, Forestry and Agricultural Biotechnology Institute (FABI), University of Pretoria, Pretoria 0002, South Africa \\ M. Craven \\ Agricultural Research Council-Grain Crops Institute, Potchefstroom 2520, South Africa
}

\begin{abstract}
Northern corn leaf blight (NCLB) is a destructive foliar disease of maize that results from infection with the fungal pathogen, Exserohilum turcicum. Annual yield losses incurred from NCLB in South Africa may exceed $50 \%$ when environmental conditions optimal for disease development prevail. In order to study the genetic diversity of E. turcicum, 13 microsatellite markers and mating type PCR primers were developed. Thirty-two primer pairs were designed from the $E$. turcicum genome sequence to flank microsatellite regions. A multiplex PCR assay amplifying both mating type idiomorphs was designed from the MAT1-1 and MAT1-2 gene sequences, and a protocol for multiplex PCR amplification of MAT loci was optimized. Initial screening identified 13 microsatellite regions that were polymorphic in 9 isolates of E. turcicum. To test the efficacy of the markers, 26 isolates of E. turcicum from 6 South African provinces, including 2 isolates from sorghum, were genotyped. A total of 90 alleles across 13 loci were obtained and the gene diversity ranged from 0.074 to 0.929 . Cross-species amplification withE. rostratum was obtained for one SSR marker (SSR27). The MAT markers were specific to E. turcicum and could be used to differentiate isolates of E. turcicum and E. rostratum. The markers developed in this study will be useful to elucidate the population genetic structure, genetic diversity and mode of reproduction of E. turcicum on maize and sorghum.
\end{abstract}

Keywords Fungi $\cdot$ Mating type markers $\cdot$ Microsatellite $\cdot$ Multiplex PCR $\cdot$ Northern corn leaf blight (NCLB) · Setosphaeria turcica

Exserohilum turcicum (Passerini) is the causal agent of North-ern corn leaf blight (NCLB), a destructive foliar disease of maize, sorghum and related grass species (Leonard and Suggs 1974). NCLB occurs globally and severe yield losses in maize are experienced when environmental conditions optimal for disease development, such as high humidity, low luminosity and moderate temperatures, prevail (Bentolila et al. 1991; Carson 1995; Levy 1991). In South Africa, yield losses of up to $70 \%$ have been attributed to NCLB infection, although annual yield losses of between 15 and $30 \%$ are most often observed (Kloppers and Tweer 2009).

Population studies provide insight into a species genetic diversity, migratory patterns, centre of origin and reproductive strategy (Ferguson and Carson 2004, 2007). These factors determine pathogen distribution and impact the length of time before the pathogen is able to overcome control measures (McDonald and McDermott 1993). Previous population studies on E. turcicum from various countries have used a multi-tude of different methods, including RAPDs, AFLP and isozymes to determine the genetic diversity of populations (Ferguson and Carson 2004; D o n g e t a 1. 2008; Muiru et al. 2010; S i m c o x e t a 1. 1993). Although microsatellite markers are considered the choice marker for population studies due to fact that they are co-dominant, selectively neutral, highly informative and reproducible 
(Chambers and MacAvoy 2000; Ellegren 2004), no such markers exist for E. turcicum. T o determine the mating type distribution of isolates in a popu-lation, mating type primers that amplify the MAT1-1 and MAT1-2 idiomorphs separately are available for E. turcicum but these amplify fragment sizes of 154 and 197 bp respec-tively (Ramathani et al. 2011).

The aims of this study were to develop robust and reproducible polymorphic microsatellite markers to study the genetic variability of E. turcicum in South Africa. In addition, the aim was to redesign the mating type primers to be used in a single multiplex PCR assay to easily and rapidly determine the mating type of isolates within E. turcicum populations.

Maize leaves displaying NCLB lesions were collected from regions within the Free State, Mpumalanga, North West, Gauteng, KwaZulu-Natal and the Northern Cape during 2007-2011. Sorghum leaves were obtained from the Free State. Leaf material was surface sterilised and incubated on moist filter paper for 4 days at $25-30{ }^{\circ} \mathrm{C}$ to induce sporulation. Single conidia were transferred to potato dextrose agar (PDA) (Merck, Darmstadt, Germany) plates and incubated for 10 days at $25-30{ }^{\circ} \mathrm{C}$ (Craven and Fourie 2011). DNA was extracted using the CTAB (cetyltrimethylammonium bromide) method as described by Murray and Thompson (1980) and adapted by Kerenyi et al. (1999). DNA was quantified with a Nanodrop 2000 spectrophotometer (ThermoFisher Scientific, Waltham, USA). The identity of the isolates were confirmed through sequencing of the internal transcribed spacer (ITS) region with universal primers ITS1 and ITS4 (White et al. 1990). Sequencing data was analysed in CLC Main Workbench version 6.9 (www.clcbio.com).

The sequenced genome of Setosphaeria turcica (Ohm et al. 2012) was screened for di-, tri- and tetranucleotide SSR repeats using MSatCommander version 2 (Faircloth 2008). Primers were designed using Primer 3 (Rozen and Skaletsky 2000) to amplify one dinucleotide and one trinucleotide repeat region from the ten largest scaffolds (2.05-4.03 Mbp), and a tetranucleotide repeat region from scaffolds one and two.

Eight $E$. turcicum isolates from maize and one from sorghum were used to test for amplification and polymorphism of SSR markers. PCR reactions were performed in $25 \mu \mathrm{l}$ using 1.5 units MyTaq (Bioline, Taunton, MA), $1 \times$ MyTaq reaction buffer (containing $5 \mathrm{mM}$ dNTPs and $15 \mathrm{mM} \mathrm{MgCl} 2$ ), 10 $30 \mathrm{ng}$ of DNA and $20 \mathrm{pmol}$ of each primer (IDT, Coralville, Iowa). Cycling conditions were $95^{\circ} \mathrm{C}$ for $3 \mathrm{~min}, 35$ cycles of $10 \mathrm{~s}$ at $95{ }^{\circ} \mathrm{C}, 10 \mathrm{~s}$ at $61{ }^{\circ} \mathrm{C}$, and $20 \mathrm{~s}$ at $72{ }^{\circ} \mathrm{C}$, with a final extension of $72{ }^{\circ} \mathrm{C}$ for $20 \mathrm{~min}$. Amplicons were sequenced to determine number of repeats and source of polymorphism. The forward primer of each marker set that amplified a polymorphic region was fluorescently labelled with dyes of the G5 filter set (Table 1, Life Technologies, Carlsbad, USA) for fragment analysis.
Three multiplex PCR reactions were designed to amplify multiple SSR markers simultaneously in a single PCR reaction. These reactions consisted of marker sets SSR20, SSR21, SSR23 and SSR26 in PCR Multiplex 1, markers SSR2, SSR6 and SSR 22 in PCR Multiplex 2, and markers SSR10, SSR24, SSR25, SSR27, SSR 30 and SSR 31 in PCR Multiplex 3.

Multiplex PCR reactions were carried out in $20 \mu \mathrm{l}$ containing $10 \mu \mathrm{l}$ Platinum ${ }^{\circledR}$ Multiplex Mastermix (Life Technologies), $0.1-0.2 \mu \mathrm{g}$ of DNA and $2 \mu \mathrm{l}$ primer mix, which consisted of equal volumes of each primer pair at optimized concentrations (Table 1). Cycling conditions were at $95^{\circ} \mathrm{C}$ for $3 \mathrm{~min}, 30$ cycles of $95^{\circ} \mathrm{C}$ for $30 \mathrm{~s}, 61^{\circ} \mathrm{C}$ for $15 \mathrm{~s}$ and $72^{\circ} \mathrm{C}$ for $1 \mathrm{~min}$, with a final extension of $60^{\circ} \mathrm{C}$ for $45 \mathrm{~min}$.

Prior to fragment analysis, $1 \mu \mathrm{l}$ of PCR Multiplex 1 and PCR Multiplex 2 were pooled together with $8 \mu \mathrm{l}$ sterile water to a total volume of $10 \mu \mathrm{l}$. Thereafter, $1 \mu \mathrm{l}$ of the diluted product was run on a single lane on the ABI PRISM 3500xl Genetic Analyzer with the LIZ500 size standard to obtain fragment sizes. PCR Multiplex 3 was diluted in a ratio of 1:9 with sterile water and run on a separate lane on the Genetic Analyzer. Alleles were scored using GeneMapper version 4.1 (Life Technologies) in two panels: fragments that amplified in PCR Multiplex 1 and 2 were scored in Panel A, and fragments that were amplified in PCR Multiplex 3 were scored in panel B (Table 1).

Allelic diversity (Nei 1973) was calculated for each locus using PopGene version 1.32 (Yeh et al. 1997). Pairwise linkage disequilibrium was tested across all loci following 1,000 randomizations using Multilocus v1.3b (Agapow and Burt 2001) to detect linked loci.

A multiplex PCR assay that could amplify both MAT loci in a single PCR reaction was developed by downloading the MAT1-1 (GenBank accession GU997138) and MAT1-2 (GenBank accession GU997137) sequences from the National Centre for Biotechnology Institute (NCBI). Primers were designed specifically to each MAT idiomorph using PrimerQuest (IDT). A reverse primer (MAT_CommonR, 5'-GTATTCCGTG TCCGCATT-3') with perfect sequence homology to regions within the 3' terminal ends of both MAT1-1 and MAT1-2 was designed. Unique forward primers that would result in amplification of different sized fragments were designed to each MAT idiomorph (MAT_1-1F, 5'-CTCGTCCTTGGAGAAGAATA TC-3'; MAT_1-2F, 5'-GCTCCTGGACCAAATAATACA-3'). The specificity of the E. turcicum MAT primers was assessed by aligning them to the mating type sequences of phylogenetically close species, as well as unrelated maize pathogens and saprophytes (Online Resource 1).

PCR amplification of the MAT genes was conducted in $25 \mu$ l, containing 2.5 units Bioline Taq Polymerase (Bioline, Taunton, MA), $2 \mathrm{mM} \mathrm{MgCl}_{2}$, and a mixture of the three primers (IDT) at a final concentration of $1 \mu \mathrm{M}$. Cycling conditions were $94^{\circ} \mathrm{C}$ for $2 \mathrm{~min}, 30$ cycles of $94^{\circ} \mathrm{C}$ for $30 \mathrm{~s}$, $61^{\circ} \mathrm{C}$ for $30 \mathrm{~s}, 72^{\circ} \mathrm{C}$ for $1 \mathrm{~min}$, followed by a final extension 
Table 1 Primer description, amplification conditions, number of alleles $\left(\mathrm{N}_{\mathrm{A}}\right)$, size ranges and gene diversity (H) (Nei 1973) for 13 primer pairs amplifying polymorphic SSR regions screened on 26 isolates of Exserohilum turcicum

\begin{tabular}{|c|c|c|c|c|c|c|c|c|}
\hline Locus & Primer sequence $\left(5^{\prime}-3^{\prime}\right)$ & $\begin{array}{l}\text { Multiplex } \\
\text { PCR and } \\
\text { panel }^{\mathrm{a}}\end{array}$ & Repeat motif & $\begin{array}{l}\text { GenBank } \\
\text { Accession } \\
\text { number }\end{array}$ & $\begin{array}{l}\text { Primer } \\
\text { concentration } \\
(\mu \mathrm{M})\end{array}$ & $\mathrm{N}_{\mathrm{A}}$ & $\begin{array}{l}\text { Allelic } \\
\text { range }\end{array}$ & $\mathrm{H}(N=26)$ \\
\hline SSR20 & $\begin{array}{l}\text { 20F-NED-GCGCGTTAATAGGGACTAGC } \\
\text { 20R-CCTGCGAAGGCGATCTATTAC }\end{array}$ & $1 \mathrm{~A}$ & ATT & KJ439653 & 0.75 & 4 & $443-455$ & 0.43 \\
\hline SSR21 & $\begin{array}{l}\text { 21F-VIC-GGTAAGTGCCGAAAGTGCC } \\
\text { 21R-TTCTGGATCCCACGGTTCG }\end{array}$ & $1 \mathrm{~A}$ & AG & KJ439654 & 0.5 & 3 & $215-223$ & 0.53 \\
\hline SSR23 & $\begin{array}{l}\text { 23F-6-FAM-CATATGCAGCGCTTGTCGG } \\
\text { 23R-AGAACTCATGGCCCTCGTG }\end{array}$ & $1 \mathrm{~A}$ & GT & KJ439656 & 0.5 & 8 & $244-258$ & 0.74 \\
\hline SSR26 & $\begin{array}{l}\text { 26F-VIC-GGACAAGTCCAGCGCAAAG } \\
\text { 26R-ATGGTATCTGGTGCCCACG }\end{array}$ & $1 \mathrm{~A}$ & AAG & KJ439659 & 0.5 & 10 & $315-383$ & 0.78 \\
\hline SSR2 & $\begin{array}{l}\text { 2F-6-FAM-ATCATACTCGGGCGTCCAC } \\
\text { 2R-TCAGCCTGCTCGACTGAAG }\end{array}$ & $2 \mathrm{~A}$ & GCT & KJ439650 & 1.25 & 2 & $433-436$ & 0.5 \\
\hline SSR6 & $\begin{array}{l}\text { 6F-PET-TGGGTGAGATCGAAGACGC } \\
\text { 6R-TCCGGTCAAACTCAAGGGC }\end{array}$ & $2 \mathrm{~A}$ & $\mathrm{ACC}$ & KJ439651 & 0.75 & 3 & $430-448$ & 0.27 \\
\hline SSR22 & $\begin{array}{l}\text { 22F-PET-GGTGCAACCTTTCTCCGAC } \\
\text { 22R-TGGCTCCAACTGGATTGGG }\end{array}$ & $2 \mathrm{~A}$ & AAT & KJ439655 & 0.5 & 4 & $324-343$ & 0.59 \\
\hline SSR10 & $\begin{array}{l}\text { 10F-NED-TCTGTGCTGAGAAGCCCAC } \\
\text { 10R-CAACCACGTGCATGATCCC }\end{array}$ & 3B & GTT & KJ439652 & 0.5 & 2 & $330-333$ & 0.07 \\
\hline SSR24 & $\begin{array}{l}\text { 24F-VIC-TGGCCACACTCTATGGCTG } \\
\text { 24R-GAGCTTGACAAACGGCGAG }\end{array}$ & $3 \mathrm{~B}$ & AAG & KJ439657 & 0.5 & 14 & $387-493$ & 0.82 \\
\hline SSR25 & $\begin{array}{l}\text { 25F-VIC-TACTCGCTAAGCACGTGGG } \\
\text { 25R-CCGTTTCCCAACTCGCATC }\end{array}$ & $3 \mathrm{~B}$ & $\mathrm{AC}$ & KJ439658 & 0.5 & 5 & $273-291$ & 0.67 \\
\hline SSR27 & $\begin{array}{l}\text { 27F-6-FAM-CAGCTTTGTCAAGGGCGTC } \\
\text { 27R-GTTCGCGACAGGTAATGGC }\end{array}$ & $3 \mathrm{~B}$ & $\mathrm{AC}$ & KJ439660 & 0.5 & 6 & 191-205 & 0.62 \\
\hline SSR30 & $\begin{array}{l}\text { 30F-PET-CACTAAACACGGCGAACGG } \\
\text { 30R-TGTCAGGGTGAAAGTGGGC }\end{array}$ & $3 \mathrm{~B}$ & AAG & KJ439661 & 0.5 & 19 & $328-449$ & 0.93 \\
\hline SSR31 & $\begin{array}{l}\text { 31F-6-FAM-TGCCTCGTATCGTGCTACC } \\
\text { 31R-CTTGGATGTGCTCTGGAAACC }\end{array}$ & $3 \mathrm{~B}$ & ACAT & KJ439662 & 0.7 & 13 & $289-431$ & 0.89 \\
\hline
\end{tabular}

${ }^{a}$ Thirteen microsatellite markers were amplified in three PCR Multiplex reactions (1, 2 and 3). PCR Multiplex reactions 1 and 2 were pooled prior to fragment analysis and run in a single lane on the ABI PRISM 3500xl Genetic Analyzer and the alleles scored in panel A in GeneMapper (Applied Biosystems). PCR Multiplex reaction 3 was run in a separate lane on the Genetic Analyzer and analysed in panel B in GeneMapper (Applied Biosystems)

step of $72^{\circ} \mathrm{C}$ for $20 \mathrm{~min}$. PCR products were separated on a $2 \%$ agarose gel run for 20-30 min at $90 \mathrm{~V}$. MAT amplicons were sequenced to ensure amplification of the correct fragment from the MAT idiomorphs.

ITS sequences obtained for 28 isolates collected from diseased maize leaves revealed that 26 were $E$. turcicum and two were E. rostratum. Both isolates from sorghum were E. turcicum. A representative sequence of the ITS region for isolate \#113 (E. turcicum) and \#317b (E. rostratum) was submitted to GenBank as accession numbers KJ380909 and KJ439663 respectively. E. rostratum isolates were used to test for cross species amplification of markers.

Thirteen primer pairs were polymorphic between isolates collected from maize (Table 1) and 19 were monomorphic (Online Resource 2). Four primer pairs were polymorphic between maize and sorghum isolates and three showed polymorphism between South African isolates and the American genome strain (ET28A) (online resource 2). Cross species amplification was only successful with marker SSR27 for
E. rostratum. Cross-amplification occurred between SSR22F and SSR20R and these two markers should therefore not be amplified in the same PCR reaction.

Fragment analysis showed that the polymorphic markers produced 90 alleles across 13 loci analysed (Table 1). The smallest and largest numbers of alleles per locus were 2 and 19, respectively. Alleles ranged from 191 to $493 \mathrm{bp}$ in length. Alleles unique to the sorghum isolates were detected in SSR6, SSR20, SSR21, SSR23, SSR24, SSR25, SSR26, SSR27, SSR30 and SSR31. Gene diversity (Nei 1973) ranged from 0.074 to 0.929 per locus, with an average diversity of 0.602 over 13 loci. Pairwise linkage disequilibrium analyses did not indicate linkage between any of the loci $(P<0.05)$.

Mating type idiomorphs were determined for the 26 isolates of E. turcicum (Table 2, Fig. 1). Amplification of isolates that were of mating type 1 (GenBank accession KJ410525) produced a fragment of $608 \mathrm{bp}$, while isolates of mating type 2 (GenBank accession KJ410526) produced a fragment of 393 bp (Fig. 1). Following gel electrophoresis, MAT1-1 was 
Table 2 Twenty six isolates of E. turcicum from South Africa used in this study

\begin{tabular}{|c|c|c|c|c|c|}
\hline & $2^{\mathrm{a}}$ & Maize & Reitz (Free State) & 2007 & MAT1-2 \\
\hline & $3^{\mathrm{a}}$ & Maize & Morgenzon (Mpumalanga) & 2007 & MAT1-1 \\
\hline & $4^{\mathrm{a}}$ & Maize & Grootpan (North West) & 2007 & MAT1-2 \\
\hline & $5^{\mathrm{a}}$ & Maize & Bloekomspruit (Gauteng) & 2007 & MAT1-1 \\
\hline & $10^{\mathrm{a}}$ & Maize & Potchefstroom (North West) & 2007 & MAT1-1 \\
\hline & $15^{\mathrm{a}}$ & Maize & Hoopstad (Free State) & 2007 & MAT1-1 \\
\hline & $23^{\mathrm{a}}$ & Maize & Bergville (KwaZulu-Natal) & 2008 & MAT1-1 \\
\hline & $30^{\mathrm{a}}$ & Maize & Vryheid (KwaZulu-Natal) & 2008 & MAT1-2 \\
\hline & $44^{\mathrm{a}}$ & Maize & Dirkiesdorp (Mpumalanga) & 2009 & MAT1-2 \\
\hline & 54 & Maize & Muiskraal (North West) & 2010 & MAT1-1 \\
\hline & 58 & Maize & Jakobsdal (Free State) & 2005 & MAT1-1 \\
\hline & 59 & Maize & Koedoeskop (North West) & 2011 & MAT1-1 \\
\hline & 60 & Maize & Brits (North West) & 2011 & MAT1-1 \\
\hline & 61 & Maize & Koedoeskop (North West) & 2011 & MAT1-1 \\
\hline & 62 & Maize & Ventersdorp (North West) & 2011 & MAT1-1 \\
\hline & 72 & Sorghum & Vredefort (Free State) & 2011 & MAT1-1 \\
\hline & 73 & Sorghum & Vredefort (Free State) & 2011 & MAT1-1 \\
\hline & $95^{\mathrm{a}}$ & Maize & Harsvallei (Northern Cape) & 2011 & MAT1-2 \\
\hline & $96^{\mathrm{a}}$ & Maize & Orania (Northern Cape) & 2011 & MAT1-1 \\
\hline & 98 & Maize & GWK 7T Rivier (Free State) & 2011 & MAT1-1 \\
\hline & 100 & Maize & GWK Perseel 3G5 (Free State) & 2011 & MAT1-2 \\
\hline & 101 & Maize & GWK Perseel 4E5 (Free State) & 2011 & MAT1-2 \\
\hline Mating types were determined & 103 & Maize & GWK Das Rambody (Free State) & 2011 & MAT1-2 \\
\hline with the mating type multiplex & 107 & Maize & GWK Skuinsland (Free State) & 2011 & MAT1-2 \\
\hline PCR assay & 110 & Maize & GWK (Free State) & 2011 & MAT1-2 \\
\hline $\begin{array}{l}{ }^{\text {a }} \text { Results of mating type PCR as- } \\
\text { sav are shown in Fig. } 1\end{array}$ & 113 & Maize & GWK Wercon (Free State) & 2011 & MAT1-1 \\
\hline
\end{tabular}

easily distinguished from MAT 1-2. In total, 14 MAT1-1 and 12 MAT1-2 idiomorphs were observed in 26 South African isolates of E. turcicum. The MAT PCR primers did not amplify in E. rostratum.

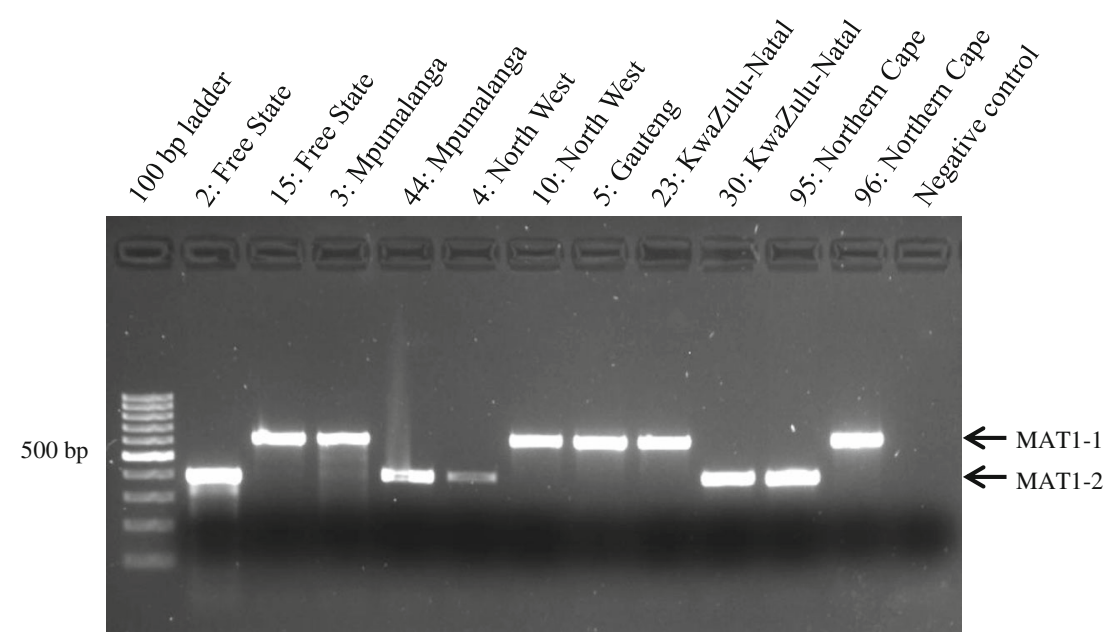

Fig. 1 Mating type determination of representative Exserohilum turcicum isolates by multiplex PCR assay. The amplicons of 608 and 393 bp represent MAT1-1 and MAT 1-2, respectively. Wells are desig-nated with the isolate number followed by the province in South Africa from where it was collected. Amplicon sizes were estimated using a 100 bpladderin lane 1 . Absence of amplification in the negative control indicated the multiplex PCR setup was free from contamination and that there was no non-specific binding between the different mating type primers 
In this study, 13 polymorphic SSR markers were developed that successfully amplified E. turcicum isolates from two host species from a wide geographical area in South Africa. In addition, a species-specific multiplex PCR assay was designed that amplifies both mating type idiomorphs of E. turcicum in a single PCR reaction, the products of which can easily be distinguished on an agarose gel. The markers developed in this study can be used to determine the population structure and mating type distribution of E. turcicum in maize and sorghum fields.

Acknowledgments This work is based on the research supported in part by the National Research Foundation of South Africa (grant specific unique reference number (UID) 85076), and by the Maize Trust and the University of Pretoria's Research and Development Programme. The financial assistance of the National Research Foundation (NRF) towards this research is hereby acknowledged. Opinions expressed and conclusions arrived at, are those of the author and are not necessarily to be attributed to the NRF. The authors are grateful to the Genomics Research Institute for financial support to Maria Haasbroek. The authors would like to thank Ms Renate Zipfel and Ms Gladys Shabangu of the sequencing facility at the University of Pretoria for technical assistance.

\section{References}

Agapow PM, Burt A (2001) Indices of multilocus linkage disequilibrium. Mol Ecol Notes 1:101-102

Bentolila S, Guitton C, Bouvet N, Sailland A, Nykaza S, Freyssinet G (1991) Identification of an RFLP marker tightly linked to the Ht1 gene in maize. Theor Appl Genet 82:393-398

Carson ML (1995) Inheritance of latent period length in maize with Exserohilum turcicum. Plant Dis 79:581-585

Chambers GK, MacAvoy ES (2000) Microsatellites: consensus and controversy. Comp Biochem Physiol 126:455-476

Craven M, Fourie AP (2011) Field evaluation of maize inbred lines for resistance to Exserohilum turcicum. S Afr J Plant Soil 28:69-74

Dong J, Fan Y et al (2008) Geographic distribution and genetic analysis of physiological races of Setosphaeria turcica in Northern China. Am J Agric Biol Sci 3:389-398

Ellegren H (2004) Microsatellites: simple sequences with complex evolution. Nat Rev Genet 5:435-445
Faircloth BC (2008) MSATCOMMANDER: detection of microsatellite repeat arrays and automated, locus-specific primer design. Mol Ecol Resour 8:92-94

Ferguson LM, Carson ML (2004) Spatial diversity of Setosphaeria turcica sampled from the eastern United States. Phytopathology 94:892-900

Ferguson LM, Carson ML (2007) Temporal variation in Setosphaeria turcica between 1974 and 1994 and origin of races 1,23, and 23N in the United States. Phytopathology 97:1501-1511

Kerenyi Z, Zeller K, Hornok L, Leslie JF (1999) Molecular standardization of mating type terminology in the Gibberella fujikuroi species complex. Appl Environ Microbiol 65:4071-4076

Kloppers R, Tweer S (2009) Northern corn leaf blight fact sheet. PANNAR Seed (Pty) Ltd

Leonard KJ, Suggs EG (1974) Setosphaeria prolata, ascigerous state of Exserohilum prolatum. Mycologia 66:281-297

Levy Y (1991) Variation in fitness among field isolates of Exserohilum turcicum in Israel. Plant Dis 75:163-166

McDonald BA, McDermott JM (1993) Population genetics of plant pathogenic fungi. Bioscience 43:311-319

Muiru WM, Koopmann B, Tiedemann AV, Mutitu EW, Kimenju JW (2010) Evaluation of genetic variability of Kenyan, German and Austrian isolates of Exserohilum turcicum using amplified fragment length polymorphism DNA markers. Biotechnology 9:204-211

Murray MG, Thompson WF (1980) Rapid isolation of high molecular weight plant DNA. Nucleic Acids Res 8:4321-4325

Nei M (1973) Analysis of gene diversity in subdivided populations. Proc Natl Acad Sci U S A 70:3321-3323

Ohm RA, Feau N et al (2012) Diverse lifestyles and strategies of plant pathogenesis encoded in the genomes of eighteen Dothideomycetes fungi. PLoS Pathog 8:1-26

Ramathani I, Biruma M, Martin T, Dixelius C, Okori P (2011) Disease severity, incidence and races of Setosphaeria turcica on sorghum in Uganda. Eur J Plant Pathol 131:383-392

Rozen S, Skaletsky H (2000) Primer3 on the WWW for general users and for biologist programmers. Methods in molecular biology (Clifton, N.J.) pp 365-86

Simcox KD, Pedersen WL, Nickrent DL (1993) Isozyme diversity in Setosphaeria turcica. Can J Plant Pathol 15:91-96

White TJ, Bruns TD, Lee SB, Taylor JW (1990) Amplification and direct sequencing of fungal ribosomal RNA genes for phylogenetics. In: PCR protocols: a guide to methods and applications. Academic, New York, pp 315-322

Yeh FC, Yang RC, Boyle T, Ye ZH, Mao JX (1997) POPGENE: The user-friendly shareware for population genetic analysis. University of Alberta, Canada: Molecular Biology and Biotechnology Centre 